\title{
Lithospheric Based Eco-decontamination and Fate Elucidation of Fungicide Fluopyram Containing Benzamides Background
}

Hamna Naeem

Fatima Jinnah Women University

Khuram Shahzad Ahmad ( $\sim$ dr.k.s.ahmad@fjwu.edu.pk)

Fatima Jinnah Women University

\section{Research Article}

Keywords: Fungicide, biodegradation, photo-degradation, hydrolysis, fate, mobility

Posted Date: February 21st, 2022

DOI: https://doi.org/10.21203/rs.3.rs-1184189/v1

License: (c) (1) This work is licensed under a Creative Commons Attribution 4.0 International License.

Read Full License 
1 Lithospheric based eco-decontamination and fate elucidation of fungicide

2 Fluopyram containing benzamides background

3 Hamna Naeem, Khuram Shahzad Ahmad

4 Department of Environmental Sciences, Fatima Jinnah Women University, Rawalpindi,

5 Pakistan

6 dr.k.s.ahmad@fjwu.edu.pk 
24 Fungicide Fluopyram (FLP) containing benzamides class has been scrutinized for the first time for 25 its ecotoxicity and environmental lithosphere stationed fate from various climatic zones. Fate26 decisive research inclusive of examining FLP's response in perspective of alteration via 27 adsorption/desorption and disintegration in hydrolytic, photolytic, and bio-degradative procedures. 28 Sorptive interactions determination was done by the batch equilibration approach and indicated its 29 dependency on the chemico-physical properties of the soils. Fragile adsorptive interactions between soils and FLP molecules were established, as indicated by physio-sorption and a fragile exothermic response indicated by negative Gibbs free energy values ( -8 to $\left.-15.3 \mathrm{~kJ} \mathrm{~mol}^{-1}\right)$. The soil with the maximal adsorption, $\mathrm{K}_{\mathrm{d}(\mathrm{ads})}=8.6 \mu \mathrm{g} \mathrm{mL}^{-1}$, was procured to have a significant organic matter content $(1.30 \%)$, resulting in a C-type isotherm that was scrutinized using a linear and Freundlich model. The analytical techniques, inclusive of ultraviolet-visible spectrophotometric and high-performance liquid chromatography procedures have been endeavored to examine FLP fate elucidation. Hydrolysis, photolysis, and biodegradation tests procured minimum halflives of 7.45, 1.29, and 5.77 days while the most remarkable were 10.6, 7.96, and 10.6 days, respectively. The results demonstrated that FLP displayed medium binding and thus low persistence in the tested soils while being extremely susceptible to transformative mechanisms. Current research can be embraced to include further augmentation of these degradative ways and to develop realistic methods for environmental cleanup through natural routes.

\section{Keywords}

43 Fungicide, biodegradation, photo-degradation, hydrolysis, fate, mobility 


\section{Introduction}

51 By 2050, the world's population will have risen to 9.4 billion people, and by 2100, it will have risen to 10 billion. The most notable feature of future demographic trends would be that the majority of population growth appears to arise in emerging Asian and African countries (Gul et al. 2020). In such areas, soil assets are insufficient in size (per capita), resistant to environmental and human activity fluctuations, and vulnerable to deterioration due to expected global warming and increased demographic stress, as well as occurring naturally dispersal (Zahid et al. 2018). Synthetic pesticides are harmful to specific species yet they can be exceptionally hazardous to non-specific species also whenever utilized unjustly. The pesticide's destiny in soils is influenced by their sorption, debasement, and permeation (Gul et al. 2020).

Increased utilization of agrochemicals for agricultural production boosts, for example, can provide farmers with short-term benefits, but the pedospheric zone is destroyed in the long run due to persistence. These contaminants not only enter the pedosphere, but also the hydrosphere and the atmosphere by leaching and vaporization. In this way, the degradation of the whole ecosystem caused by chemicals is linked to long-term environmental harm. In light of the environmental disruptions caused by smaller chemicals, scientific research disciplines must seek to classify and apprehend toxic chemical fates, as well as formulate effective management strategies for environmental security (Iram et al. 2019, 2020).

FLP is a benzamide-class compound that inhibits succinate dehydrogenase and was initially used as a fungicide (Waisen et al. 2021; Meza et al. 2021; Grabau et al. 2021). FLP has been widely used in agriculture and has toxicological effects on non-target organisms (Liu et al. 2021). Bayer Crop Science developed FLP, a new broad-spectrum fungicide in the benzamide class (Matadha 72 et al. 2019; Liang et al. 2021). FLP is extremely helpful in combating a wide range of pathogens in over 1970 plants, including crop plants, vegetables, vines, and some grapes, primarily by restricting the SDH, parasitic and fungal, and chain of parasitic respiratory (Liu et al. 2021).

The bipyridine molecule with the trifluoromethyl group has outstanding pharmacological action 76 and has a wide range of applications in medicine and pesticide production (Robatscher et al. 2019).

77 FLP has a lengthy half-life in soil, up to 746 days, which is significantly longer than that of typical 78 nematicides (PPDB, 2019). Because of its weak high soil adsorption coefficient and solubility, 
FLP has weak soil mobility (Faske et al. 2019). FLP's impacts on terrestrial and aquatic animals, 80 such as rats, non-target nematodes, and fish, have been studied extensively (Waldo et al. 2019). In 81 tropical farmlands, FLP is often used to treat scab, anthracnose, and banana leaf spot (Zhou et al. 82 2021).

The current climate is constantly deteriorating ( $\mathrm{Ijaz}$ et al. 2020). Over the last few decades, a variety of fungicidal products are used and developed to fight a variety of fungal microbial microorganisms that have destroyed crops in different regions of the world. New energy options are being pursued the good of the human population in the current period of increased industrialization and urbanization (Jaffri and Ahmad 2020). Along with resources, the primary demand is for food, which is traditionally met by the use of mechanized farming methods and agrochemicals. Even so, the deterioration of environmental quality as a result of the use of such long-lasting synthetic pesticides cannot be ignored. A detailed and meticulous understanding of pesticide activity in soils and other compartments is critical in this regard. When exposed to various environments, the pesticide's sorptive is considered. Following that, pesticide control may be carried out. Pakistan's agricultural economy is known for exporting large cash crops thanks to its fertile lands ideal for farming (Iram et al. 2020).

In Pakistan, the indiscriminate use of pesticides is also an inevitable problem that is damaging ecological health. Even so, despite this increased use, there is a paucity of research on the fate and action of FLP fungicide in soils. As a result, the current study is the first to focus on the FLP fungicide to investigate its ecological activity in tested soils. In vitro testing in a lab was used to determine the adsorption, desorption of the tested soils for this purpose. The abiotic pathways of FLP fungicide modification were sorption, hydrolysis, photodegradation, and soil biodegradation. The pedospheric samples were selected from agriculturally important regions in Pakistan, which are renowned for their agricultural production. 


\section{Materials and methods}

\section{Reagents and chemicals}

The overall methodology has been depicted in Fig. S1. The chemicals utilized in this research were inclusive of $\left(\mathrm{CH}_{3}\right)_{2} \mathrm{CO}, \mathrm{CH}_{3} \mathrm{OH}$, anhydrous $\mathrm{NaCl}, \mathrm{Na}_{2} \mathrm{SO}_{4}, \mathrm{CaCl}_{2}$, and analytical grade fungicide FLP procured from Germany (Dr. Ehrenstorfer, Augsburg). Three dimension structure of FLP is shown in Fig. S2. Deionized water was utilized to make the FLP stock solution. For the analysis, a UV-Vis spectrophotometer (Bms(-1602)) was used. The extracts were analyzed using HPLC (Schimadzu LC20AT). The quantification wavelength was chosen to be $270 \mathrm{~nm}$ absorbance. The temperature and flow rate was maintained at $30{ }^{\circ} \mathrm{C}$ and $1 \mathrm{~mL} / \mathrm{min}$ with an injection volume of 20 $\mathrm{uL}$.

\section{Soil analysis}

Distinct samples of soil were taken from ten different Pakistani regions, including: (Fig. 1). Soil samples were taken with a manual handheld betoken from a depth of 0-20 cm, kept at $4{ }^{\circ} \mathrm{C}$, and placed in plastic bags. The samples were desiccated in the open air then delivered through a $2 \mathrm{~mm}$ strainer before being stored in impenetrable containers for further testing and experiments. Heavy metal research, total nitrogen (TN), total organic carbon (TOC), electrical conductivity (EC), $\mathrm{pH}$, and organic matter $(\mathrm{OM})$ were all included in the physicochemical investigation of soils. The inclusive adopted methodology in the present investigation is displayed in Fig. 2.

\section{FLP stock solution and dilutions}

For the sorption experiments, an FLP stock solution was produced.10.3 $\mathrm{g}$ of FLP was dissolved in $1000 \mathrm{~mL}$ of DW to make a $10 \mathrm{ppm}$ FLP solution with five drops of acetone. The reaction mixture was then magnetically stirred for 24 hours. Eight dilutions, namely 0, 0.25, 0.5, 0.75, 1, 2.5, 5, and $7.5 \mathrm{ppm}$, were taken from the stock solution and with a $100 \mathrm{~mL}$ capacity elevated to the mark in a round-bottom flask. Then $10 \mathrm{~mL}$ of $0.1 \mathrm{M} \mathrm{NaCl}$ was introduced to these ionic strength adjustment dilutions (Naeem et al. 2020).

\section{FLP adsorption and desorption}

The batch equilibrium method was utilized to evaluate the adsorption process in soil, using sixteen falcon tubes. One blank and one control sample were made to examine soil impurity or any other 
intrusion which would outcome in matrix effect. Vials were stirred for 24 hours at 90 RPM at room temperature in an orbital shaker. After shaking they were centrifuged at 3500 RPM for 20 minutes then filtered via $0.2-\mu \mathrm{m}$ nylon filters. A UV-Vis spectrophotometer was used to examine clear aliquots.

Supernatant from the vials was discarded, reweighed and then the pesticide-soil blend was utilized to observe the desorption activity. In vials, $9 \mathrm{~mL}$ of $0.1 \mathrm{M} \mathrm{CaCl}_{2}$ was inserted. The desorption behavior was studied using UV-Vis spectra after shaking and centrifugation. UV-Vis values were used to analyze the data, Freundlich and linear isotherms were used for the analysis of UV data (Gul et al. 2021).

\section{FLP hydrolysis}

In a $100-\mathrm{mL}(10 \mathrm{ppm})$ volumetric flask, the fungicide FLP was hydrolyzed by adding $5 \mathrm{~g}$ of each soil. To avoid microbiological contamination and achieve results that were exclusively due to hydrolysis, the containers were covered with parafilm tape. The reaction mixture assemblage was continually stirred and incubated at room temperature in a batch. Soil samples were extracted at regular intervals and subjected to elimination utilizing $2 \mathrm{~mL}$ DCM two times, followed by the inclusion of anhydrous $\mathrm{Na}_{2} \mathrm{SO}_{4}$ to prevent moisture from penetrating the experimental setup. Filtered samples were subjected to an evaporation method in a fuming hood to obtain the required quantity, which was then stored in the refrigerator and analyzed using spectrophotometric techniques (UV-visible) to determine the hydrolytic behavior of FLP fungicide in aqueous media (Naeem et al. 2020).

\section{FLP photolysis}

Different dilutions of the fungicide FLP were used to observe photo-induced breakdown. Two batches were set up for these studies to observe the role of photonic species in causing breakdown: The first batch of experiments was done in a light-induced environment, while the second batch was done in a dark environment. The reaction vials were filled with $10 \mathrm{~mL}$ of DW and $0.1 \mathrm{mg}$ of FLP in both assemblages. Photolytic degradation was performed under solar irradiation from noon onwards when the sun shone brightly. The average intensity, as determined by a digital lux metre, was 70-75 klux (LT300, Extech, Leeds, UK). Spectrophotometric (UV-Vis) and spectroscopic 
164 (HPLC) techniques were used to examine samples subjected to light and dark environments 165 (Naeem et al. 2020).

\section{FLP soil biodegradation}

167 The inherent capacity of topsoil microorganisms for FLP debasement was assessed using topsoil 168 inherent debasement. FLP soil degradation was observed by topsoil's intrinsic microfauna in all

169 ten collected soils without the use of any natural materials or debasing microbial consortium. The 170 current study involved no bio-augmentation. In Petri dishes, soil samples were placed, followed 171 by $10 \mathrm{~mL}$ of stock solution. To achieve natural conditions, the Petri dishes were sealed off and 172 put in a greenhouse under daylight and temperature. Extraction was done with dichloromethane 173 and examined for degradation using UV-Vis to identify metabolites during this time (Naeem et al. 174 2020).

\section{Data analysis}

176 The below equations were used to measure the adsorption and desorption rates of pesticides in 177 various samples.

$$
C_{S}=\mathrm{V} / \mathrm{m}\left(C_{b}-C_{e}\right)
$$

179 where $\mathrm{C}_{\mathrm{s}}$ represents the sum of adsorbed fungicide, $\mathrm{V}$ represents the volume of soil solution, $\mathrm{m}$ 180 represents soil mass $(\mathrm{g}), \mathrm{C}_{\mathrm{b}}$ represents equilibrium concentration of blank, and $\mathrm{C}_{\mathrm{e}}$ represents 181 equilibrium concentration of supernatant suspension. After equilibration, the amount of fungicide 182 adsorbed in the soil in $\mathrm{g} / \mathrm{g}$ was calculated by subtracting the blank value from the pesticide residual 183 present in the solution. The following equation was used to calculate $\mathrm{K}_{\mathrm{d}}$ for adsorption and 184 desorption (Janaki et al. 2015);

$$
K_{d}=C_{s} / C_{e}
$$

where $K_{d}$ is linear sorption equilibrium distribution coefficient $(\mu \mathrm{g} / \mathrm{mL}), C_{s}$ is the concentration of adsorbed pesticide $(\mu \mathrm{g} / \mathrm{mL})$, and $\mathrm{C}_{\mathrm{e}}$ is the equilibrium concentration of supernatant equilibrium $(\mu \mathrm{g} / \mathrm{mL})$. The Freundlich equation for determining pesticide adsorption isotherms is shown below (Dal Bosco et al. 2012).

$$
C_{s}=K_{f} C_{e} 1 / n
$$


191 where $\mathrm{C}_{\mathrm{e}}$ refers to equilibrium concentration $(\mu \mathrm{g} / \mathrm{mL}), \mathrm{C}_{\mathrm{s}}$ is the sum of pesticide adsorbed $(\mu \mathrm{g} / \mathrm{mL})$, $192 \mathrm{~K}_{\mathrm{f}}$ refers to Freundlich adsorption coefficient, $\mathrm{n}$ is the constant, and $1 / \mathrm{n}$ refers to Freundlich 193 adsorption isotherm's slope. The Freundlich coefficient expressed normalized with organic carbon 194 in Eq. 4 (Takeshita et al. 2020);

$195 \quad K_{f o c}=K_{f} /$ OC $\times 100$

196 Linear coefficient synchronized with organic carbon in Eq. 5 (Hu et al. 2019);

$197 \quad K_{o c}=K_{o c} \% C \times 100$

$198 \mathrm{OM}$ distribution coefficient calculated by normalizing $\mathrm{K}_{\mathrm{d}}$ with organic carbon content in Eq. 6 199 (Liu et al. 2010);

$200 \quad K_{o m}=K_{d} \% O M \times 100$

$201 \quad K_{\text {fom }}=K_{f} / \% O M$

$202 \mathrm{H}=n_{d} / n_{a}$

203 where $H$ refers to adsorption isotherm's Hysteresis coefficient, and $n_{d}$ and $n_{a}$ are constants (Liu et 204 al. 2010).

$205 \mathrm{G}=-\mathrm{RT}$ In $K_{\text {om }}$

206 The Gibbs free energy is denoted by $\mathrm{G}(\mathrm{kJ} / \mathrm{mol})$. It's a critical thermodynamic parameter for the 207 completion of sorption studies. FLP degradation kinetics is calculated using first-order reaction 208 kinetics s (Gul and Ahmad 2018);

$209 \ln \left(\mathrm{C} / C_{0}\right)=-\mathrm{kt}$

210 the percentage degradation of FLP was calculated using (Gul and Ahmad 2020);

$211 D_{t}=\left[\left(S_{b}-S_{a}\right) / S_{b}\right] \times 100$ 
$212 D_{t}$ refers to FLP degradation percentage, $S_{a}$ refers to residual FLP in the sample, and $S_{b}$ is the 213 pesticide in a controlled sample. $\mathrm{t}_{1 / 2}=0.693 / \mathrm{k}$ was used to measure the half-life. MINITAB 17

214 (Statistical Software, USA) was used to conduct statistical research (multivariate analysis and 215 ANOVA, principal component analysis, and biplots) on the sorption coefficient ( $\mathrm{K}_{\mathrm{d}}$ ), FLP 216 degradation rates soil and physicochemical properties.

\section{Results and discussion}

218

219

220

221

222

224

225

226

In nature, various types of reactions occur within soils at varying rates. Soil, as a recipient medium for a variety of toxins and contaminants, reacts in a variety of ways. This identifies the unique function of soils around the world in terms of various contaminants. During agricultural actions, soils are also exposed to pesticides. Pesticides and other agrochemicals must be assessed for their activity due to their longevity in nature and eventual entry into the human food chain so that they can be handled in a way that ensures their economic viability and sustainability (Jaffri et al. 2019a). In this context, determining the fate of any pesticide is an important step before management. The fate of the benzamide fungicide FLP was investigated using adsorption/desorption, hydrolysis, photolysis, and biodisintegrative mechanisms. The tested soils were assessed for physicochemical features before understanding FLP fate, as indicated in Table 1.

\section{Lithospheric physicochemical properties}

The environment and long-term sustainability are inextricably related. Long-term benefits are associated with the adoption of sustainable practices (Jafri and Ahmad 2020). Though, this is focused on previous research of the polluted ecological matrix. The pedospheric area receives a substantial volume of toxins and toxic chemicals. Soils that have been developed by various geochemical procedures also demonstrate distinct physical and chemical characteristics. These characteristics are significant from a remedial perspective because they have a significant effect on pollutant entry and transport across the lithospheric zone. Investigation of physicochemical features of soil is indispensable because they influence all FLP degradative phenomena in soils. As a result, they might be regarded significant information in estimating the fate of any chemical in the lithospheric region (Zahra et al. 2017). The soil physicochemical properties are vital in determining the pesticide-soil relationship. The characteristics also aid in investigating the dispersive way of pesticides in the lithosphere (Gul et al. 2020). Exploring the physicochemical characteristics of tested soils is a 
241 significant part of understanding the fate of fungicide FLP in the selected pedosphere and planning remedial stages in the procedure of chemico-physical and biological procedures. FLP pedosphere fate is affected by the physicochemical composition of the soil. The extensive variety of observations is illustrated across all soils. The $\mathrm{pH}$ of all samples varied from 7.30 to 7.73 and is indicative of the neutral tendency. S4 had a slightly alkaline $\mathrm{pH}$ (7.73). The soil OM is inconsistent in all regions. S8 and S9 $(1.3,1.25 \%)$ portrayed the highest OM content, while S4 displayed the lowest $(0.30 \%)$. A strong source of naturally decayed leaf litter may also be from OM in S8 (Arshad et al., 2017). The fertility of the soil is investigated by the content of carbon and nitrogen. Increased soil organic carbon (OC) lowers lethality and allows plants to thrive (Gul et al. 2020). S8, S9 exhibited the highest OC at 0.75 and 0.72 respectively. The lowest OC was obtained in S4 at 0.174 . Table 1 lists the various physicochemical properties that influence its behavior in the soils studied in this study. The amount of EC ranged from 0.68 to $1.61\left(\mathrm{Sm}^{-1}\right)$. S5 $\left(1.61 \mathrm{Sm}^{-1}\right)$ and S9 $\left(1.43 \mathrm{Sm}^{-1}\right)$, received significant amounts of EC. These soils exhibited a high level of salinity. Since S10 $\left(0.68 \mathrm{Sm}^{-1}\right)$ and S2 $\left(0.69 \mathrm{Sm}^{-1}\right)$ portrayed less EC value, they have the least amount of saltiness, whereas other soils depicted an intermediate scale. The majority of the soils in the Chakwal district are light-grained sandy loom and sandy clay loom types. The soils in the alluvial terraces and area and dissected ancient loess are silt loam and silt in texture, with $\mathrm{pH}$ levels ranging from 7 to 9 (Siddiqui et al. 2020). The presence of heavy metals in soil samples is indicative of the presence of industrial activities in the region. Cd levels were found to be the highest in S5 (0.16 ppm). $\mathrm{Cu}$ levels were highest in S9 that was 4.1 ppm and S5 was 2.88 ppm and lowest in S2 (1.1 ppm) and S3 (0.83 ppm). The concentration of Fe was found to be high in S5 (19.2 ppm) and the lowest concentrations in $\mathrm{S} 9$ (16 ppm). The $\mathrm{S} 9$ and $\mathrm{S} 5$ soil samples contained significant $\mathrm{Pb} . \mathrm{Pb}$ has been designated as one of ten substances of considerable public health concern by the World Health Organization (WHO) (Anwar et al. 2020). Cd is a heavy metal that binds firmly to organic materials and is immobile in soil. However, it is absorbed by plant life and ultimately enters the food supply since it bioaccumulates at many stages of the food chain (Khwaja et al. 2020). Cd is utilized as an alloy in automotive carburetors and accumulators and, as a consequence of the combustion process in the vehicle engine, it makes its way to the atmosphere from there. Trafficrelated exhaust is a source of soil pollution by $\mathrm{Pb}$. Vehicular exhaust, corrosion of the brake pad, tire abrasion, and lubricating oil are due to copper contamination (Shehzad et al. 2019).

\section{Adsorption behavior of FLP-soil}


272 The utilization of linear and Freundlich adsorption plots confirmed the fungicide's multiple-

273 layered sorption mode. The augmented regression values verified the best fit of sorption in the 274 tested soils with the additional models.

\section{Linear model}

276

The adsorption of FLP using a UV-Vis spectrophotometer in the tested soils was assessed in light of the soil's physicochemical parameters. Isothermal graphs versus equilibrium concentration and amount of FLP adsorbed were plotted using analytical values procured from UV-Vis. The linear and Freundlich models were utilized to investigate the adsorption of FLP (Fig. 3 and Table 2). Multilayer surfaces, such as soils, are known to behave as adsorption media for a range of contaminants and toxins, and these models are utilized to simulate them. The adsorption distribution coefficient $\left(\mathrm{K}_{\mathrm{d}(\mathrm{ads})}\right), \mathrm{K}_{\mathrm{om}}$, and $\mathrm{K}_{\mathrm{oc}}$ were the adsorption characteristics studied in the linear adsorption model. Table 2 is indicative of these characteristics clarified the actions and interactions of FLP fungicide with soils. $\mathrm{K}_{\mathrm{d}}$ adsorption coefficient ranged from $0.45 \mu \mathrm{g} / \mathrm{mL}-8.6$ $\mu \mathrm{g} / \mathrm{mL}$, having an $R^{2}$ of 69-91.5. In the tested soils, fungicide FLP adsorption followed a C-type isotherm, that is conformation with C-type isotherms procured for earlier examined benzamides pesticides. The significant adsorption of FLP fungicide molecules in the selected soils was indicated by the C-type isotherm. Freundlich model was shown to be the best fit for adsorption. S8 depicted the lowest mobility, suggesting a greater rate of adsorption. Because of the low adsorption, the highest mobility was observed in S4. The results of the "C"-type isotherm indicated that soil physicochemical parameters may have a greater influence on the rate of soil adsorption (Zhou et al. 2019). S8 portrayed $8.6 \mu \mathrm{g} / \mathrm{mL} \mathrm{K}_{\mathrm{d}(\mathrm{ads})}$ whereas $\mathrm{S} 4$ displayed the lowest $0.45 \mu \mathrm{g} / \mathrm{mL}$ $\mathrm{K}_{\mathrm{d}(\mathrm{ads})}$. The mobility of fungicides poses a significant challenge in determining FLP's ecological fate.

The mobility pattern of FLP was investigated using adsorption experiments by the calculation of FLP $\mathrm{K}_{\mathrm{oc}}$ and $\mathrm{K}_{\text {foc }}$ parameters in selected samples. Fungicides with a $\mathrm{K}_{\mathrm{oc}}$ below 50 are considered extremely mobile, whereas those between 150 and 500 are considered moderately mobile (Naeem et al. 2020). The $\mathrm{K}_{\mathrm{oc}}$ of FLP was classified into a medium and low mobility group based on the investigational analysis of samples collected. A significant $\mathrm{K}_{\mathrm{oc}}$ was found in $\mathrm{S} 8(844 \mu \mathrm{g} / \mathrm{mL})$, indicating low FLP mobility in topsoil sampling. Furthermore, low mobility reduces the risk of contamination of groundwater sources. For soil sampling, the distribution coefficient $\left(\mathrm{K}_{\mathrm{om}}\right)$ was 
investigated. The $\mathrm{K}_{\mathrm{om}}$ rate has already been given precession in various studies because it reduces variance. In the present investigation, $\mathrm{K}_{\mathrm{om}}$ varied from 26 to $492 \mu \mathrm{g} / \mathrm{mL}$. FLP adsorption in terms of $\mathrm{K}_{\mathrm{d}}$ revealed the following order: $\mathrm{S} 8>\mathrm{S} 9>\mathrm{S} 7>\mathrm{S} 3>\mathrm{S} 2>\mathrm{S} 10>\mathrm{S} 1>\mathrm{S} 5>\mathrm{S} 6>\mathrm{S} 4$. The level of variability was expressed in terms of the adsorptive surfaces subjected to FLP by $\mathrm{n}_{\mathrm{a}}$ (Hasan et al. 2019). Linear curves are formed when the values of $n_{a}$ are 1 . Non-linear curves can be attributed to specialized interactions occurring between pesticides (polar groups), mineral interfaces in soils, and adsorbent organics in the instance of several pesticides. When there is greater variety in aspects of soil surface heterogeneity, greater energy adsorbent surfaces are more likely to be occupied, followed by those with reduced energy points (Conde-Cid et al. 2019).

Soils mark a diverse substrate consisting of parent rocks, minerals, and non-crystalline components transported in from the outside environment. As a result, evaluating various soil processes is likewise a strenuous task. The standard Gibbs free energy $(\Delta \mathrm{G})$ recognized for exhibiting the transferal of FLP fungicide molecules between the aqueous and solid phases was utilized to assess the thermodynamic feature of the fungicide. $\Delta \mathrm{G}$ explains the relations between soil particles and fungicides. The results procured for $\Delta \mathrm{G}$ are $\leq-40 \mathrm{~kJ} / \mathrm{mol}$, and are indicative of the presence of physisorption, whereas values above this value depict the presence of chemisorption. In the current analysis, $\Delta \mathrm{G}$ values ranged from 8 to $15.3 \mathrm{~kJ} \mathrm{~mol}^{-1}$. Such characteristics are demonstrative of a lack of adsorption through Van der Waal's forces or hydrogen bonding. In this way, three-carbon cores and the framework's ring work together (Aftab et al. 2021).

\section{Freundlich model}

The Freundlich model was subsequently utilized to investigate the adsorption interactions that formed between the FLP fungicide and the 10 selected soils. In conformance with the linear model, the Freundlich model also revealed significant FLP adsorption in the chosen soils, with Freundlich adsorption coefficients $\left(\mathrm{K}_{\mathrm{f}}\right)$ spanning from $0.00112 \mu \mathrm{g} / \mathrm{mL}$ to $8.86 \mu \mathrm{g} / \mathrm{mL}$ and $R^{2}>0.57$ indicating the best fit of the findings. Freundlich's adsorption process was also functional in tested soil samples (Fig.3b). The $\mathrm{n}_{\mathrm{a}}$ value was procured from the regression condition and was between 0.27 and 1. S9 had the highest levels of $n_{a}$. Dal Bosco et al. reported that Brazilian topsoils showed $n_{a}$ near 1. Low $\mathrm{K}_{\mathrm{f}}$ is also accompanied by a low $\mathrm{n}_{\mathrm{a}}$ (Kodešová et al. 2011). The sum of $\mathrm{n}_{\mathrm{a}}$ in the $\mathrm{S} 5$ was lower. In $\mathrm{S} 5(0.00112 \mu \mathrm{g} / \mathrm{mL})$, the assessment of $\mathrm{K}_{\mathrm{f}}$ was found to be negligible. Fungicide adsorption in Chinese topsoils has been reported and its result revealed a relationship in adsorption 
332 in Pakistani soils. $\mathrm{K}_{\mathrm{f}}$ estimate stated to be low in Indian soils (Shivaramaiah 2014). According to

333 Janaki et al. (2017), $\mathrm{pH}$ and $\mathrm{K}_{\mathrm{f}}$ values have an inverse relationship. Owing to larger variation in 334 physicochemical characteristics and the impact of climatic conditions and microbial fauna, $\mathrm{K}_{\mathrm{f}}$ 335 reading from preceding study from China and India possibly will be inferred that Pakistani soils 336 exhibited a complex behavior to FLP adsorption in Pakistani soils, presenting an extreme to the medium pattern.

\section{Linear and Freundlich desorption isotherms}

Because the FLP molecules are strongly bonded to soils' adsorptive surfaces and thus their removal is complex, the extent of FLP desorption in soils is frequently represented oppositely to that of adsorption, i.e., soils exhibiting remarkable adsorption exhibit lower desorption. Similarly, soils with fragile adsorption have a significant desorption extent because it is easier to remove the loosely bound FLP molecules in this scenario. The UV-Vis results for FLP desorption were also analyzed utilizing linear and Freundlich models, and graphs were drawn to show the relationship between equilibrium concentration and FLP desorbed. Desorption distribution coefficient $\left(\mathrm{K}_{\mathrm{d}(\mathrm{des})}\right)$, $\mathrm{n}_{\mathrm{d}}$, and hysteresis $(\mathrm{H})$ were investigated in linear and Freundlich desorption, as indicated in Table 3. Fig. 3 is expressive of the comparison curves for linear and Freundlich desorption models. The values of the desorption distribution coefficient ranged from $4 \mu \mathrm{g} / \mathrm{mL}$ to $20.7 \mu \mathrm{g} / \mathrm{mL}$. With a desorption extent of $20.7 \mu \mathrm{g} / \mathrm{mL}$, S9 showed significant desorption, whereas $\mathrm{S} 1 \mathrm{~K}_{\mathrm{d}(\mathrm{des})} 4.2 \mu \mathrm{g} / \mathrm{mL}$ showed the least. $\mathrm{S} 1<\mathrm{S} 2<\mathrm{S} 8<\mathrm{S} 5<\mathrm{S} 4<\mathrm{S} 10<\mathrm{S} 6<\mathrm{S} 7<\mathrm{S} 3<\mathrm{S} 9$ was the overall trend for FLP desorption in the tested soils. The Freundlich desorption coefficient $\left(\mathrm{K}_{\mathrm{f}}\right)$ was indicated to be between $12.3 \mu \mathrm{g} / \mathrm{mL}-74.4 \mu \mathrm{g} / \mathrm{mL}$. The lowest $\mathrm{K}_{\mathrm{f}}$ value was obtained in $\mathrm{S} 8(12.3 \mu \mathrm{g} / \mathrm{mL})$, while the highest value was observed in $\mathrm{S} 1(74.4 \mu \mathrm{g} / \mathrm{mL})$. The lowest $\mathrm{n}_{\mathrm{d}}$ value $0.72 \mu \mathrm{g} / \mathrm{mL}$ was detected in $\mathrm{S} 8$, while the highest was reported in $\mathrm{S} 1(2.13 \mu \mathrm{g} / \mathrm{mL})$. The hysterical nature of FLP association with soils is confirmed by $\mathrm{H}$ values, indicating the irreversibility of the responses (Yavari et al. 2020). The hysterical behavior demonstrated good FLP's adhesion to soil particles, as well as the

357 fact that it cannot be easily removed using various remediation approaches. H was estimated at the 358 lowest level in S9 (0.5), and at the highest level in S5 (2.1).

\section{Effect of physicochemical properties of soil on sorption of FLP}


Chemical and physical properties, on the other hand, have a significant effect on sorption behavior; however, the main parameters influencing FLP's sorptive behavior with tested samples are EC, $\mathrm{pH}$, clay, and $\mathrm{OM}$. The electric interaction between pesticides molecules, charged particles, and soil particles are because of physical adsorption (van der Waals forces) or chemical adsorption (electrostatic interactions). Pesticide particles that have a negative charge bind with positively charged particles in the soil. Sandy soils, according to previous research, have lower adsorption because of pores having large sizes they fail to retain the new molecules ( $\mathrm{Li}$ et al. 2019). These physicochemical aspects that contribute to FLP adsorption add to the fragile desorption pattern by powerfully connecting the FLP particles and making it difficult to isolate them from the multilayer assortment of soils, resulting in FLP's hysterical sorptive behavior. As a result, physical or chemical standards tend to overpower FLP desorption, which is categorized by an irreversible reaction and desorption of FLP. Because of the OM and clay concentration in the soil sample, the newly arriving FLP pesticide molecule has an extra active site for greater attachment, hence the adsorption rate rises due to Van der Waals forces or hydrogen bonding Van der Waals forces. The S8 sample contained most of the OM content having the highest percentage of FLP adsorption. Soil S4 and S6 showed a slow rate of adsorption, showing an inverse relationship between adsorption rate and $\mathrm{pH}$. The presence of a lot of clay in the soil helps in sticking pesticide particles. Soil has a low adsorption rate due to less clay content (Abdelwaheb et al. 2019). Pesticide adsorption was found to be less concentrated in soils with a greater $\mathrm{pH}$. Low $\mathrm{pH}$ soils have a larger protonated surface zone on the adsorbent. Soils have a higher proclivity for buffering contrary to $\mathrm{pH}$ changes this is due to high OM content (Gul et al. 2021). More OM soils have a better chance of being useful to underground water since more molecules can bind to natural soil along these lines, preventing fungicides from sifting into underground water. Fungicides prefer $\mathrm{OM}$ as a sorptive substrate because hydrophobic relations facilitate stage parting. Various studies have shown a clear association between adsorption level and OM (Herrera et al. 2019). Due to irreversible responses, hysteresis activity became more prevalent as FLP concentration increased. A comparison of the adsorption coefficient with $\mathrm{OM}$ and $\mathrm{pH}$ shows that as adsorption increases, $\mathrm{pH}$ decreases steadily, favoring the results of an inverse relationship between $\mathrm{pH}$ and $\mathrm{OM}$. A direct association between organic material and coefficient of adsorption was also discovered when the coefficient of adsorption increased as the OM content increased.

\section{FLP hydrolytic response}


Hydrolysis has been examined for a variety of pesticides and is commonly connected with organic processes and electrical processes (Feng et al. 2020; Pérez-Mayán et al. 2020). Natural hydrolysis of diverse manmade compounds in the hydrospheric and lithospheric regions is an important process that results in the disintegration of chemicals at varying speeds. After infiltrating soils, all chemicals, including pesticides, are subjected to natural degradation in this manner. Many agrochemicals, including pesticides, have been investigated for their hydrolytic reaction, including electrical and organic mechanisms (Song et al. 2019). Such inquiries are based on the rate orders' determination. Even though there is no influence of half-life on pesticide concentration, kinetics first-order reactions have been determined for hydrolytic degradation, which is indicative of the direct proportionality between concentration and pesticide hydrolytic rate in aqueous environments (Briceño et al. 2020). Previous research in this dominion has demonstrated the necessity for augmented pesticide concentrations to influence hydrolytic mechanisms (Scheunert 2018). The medium trend for hydrolysis detected in all chosen soils was suggestive of FLP hydrolytic breakdown via hydrolysis, indicating that optimum temperature can appropriately activate the hydrolytic process. A significant hydrolysis rate was observed in S1 (93 \%) as shown in Table 4. Any soil with a high sand content provides a fragile adsorption site, and the inability to attach to the nearby soil particles causes the FLP molecules to move in the soil matrix, giving them an obvious mark for hydrolysis. The results for FLP hydrolysis demonstrate a substantial dependency on sorption of FLP with soil particles, as well as a dependency on soil physicochemical methods. As a result, FLP compounds bound to soil constituents can be hydrolyzed if incorporated in the nearby soil. The constant hydrolysis rate $(\mathrm{k})$ extended from 0.065- 0.093, indicating the hydrolytic process' direction and speed. Since different results and trends were provided in this condition, making it tough to make a definitive report on FLP hydrolysis in topsoil, specific samples were taken to estimate FLP hydrolytic processes. The current study's findings focus solely on FLP's behavior in the soil matrix. Because the presence of several microbial and small invertebrate species under naturalistic environments cannot be prevented, the hydrolysis rate inside the pedospheric matrix is generally confronted with a variety of parameters in the context of other pesticides and agrochemicals. As a result, different pesticides have diverse hydrolytic processes (D'Andrea et al. 2020; Muff et al. 2020). Previous research with other fungicides indicated that hydrolytic degradation occurs via chemical and microbiological mechanisms (Wang et al. 2020). 


\section{FLP photolytic response}

423 Photonic reactions caused by sun irradiation on the earth's surface operate at varying rates, are driven by different mechanisms and are linked to the degradation of diverse contaminants. Pesticides are among the contaminants that fall within this category. By conducting two sets of experiments, the reaction of FLP to incident sunlight was investigated. The set subjected to light was significantly affected as determined via UV-Vis demonstrating a significant decline in the absorptive pattern derived at various time intervals of light exposure, whereas the set exposed to darkness exhibited negligible deterioration. The rate order was calculated by UV-Vis-based analysis findings utilizing $\ln \left(\mathrm{C}_{\mathrm{t}} / \mathrm{C}_{\mathrm{o}}\right)$ formula displayed in Fig. 6 . The photo-physical disintegration of FLP is characterized by first-order reaction kinetics. The advancement of sustainable development goals is linked to the photolytic degradation of chemical substances (Tahir et al. 2019a; Zafar et al. 2020; Siraj et al. 2020). FLP photolytic disintegration is critical for ecological decontamination of lithospheric matrices polluted with it without utilizing costly and complex remedial technologies characterized by the need for vast locations and hefty capital expenditures. The implementation of such complicated technologies is unnecessary due to the simple and spontaneous degradation of FLP in the soil profile. Moreover, FLP's photo-degradation inhibits it from draining down to lower soil layers, leading to insignificant leaching in the vertical direction. Furthermore, this form of degradative mode inhibits plants from uptaking FLP, naturally reducing the risk of translocation. Table 5 displays the rate constants, regression coefficients, and half-life of the chosen samples, with the minimal half-life $\left(\mathrm{t}_{1 / 2}\right)$ and maximum rate constant $(\mathrm{k})$ in concentration, $5 \mathrm{mgL}^{-1}$. The $7.5 \mathrm{mg} / \mathrm{L}$ concentration portrayed the maximal half-life $\left(\mathrm{t}_{1 / 2}\right)$ and minimal rate constant (7.96 days and 0.087 , respectively). The presence of the greatest concentration of FLP is responsible for such a phenomenal photo-degradation. The results of FLP's hydrolysis revealed an interesting fact that its dilapidation was comparably profound to that observed in photolysis. The final extract of photo-degradation was subjected to HPLC analysis to determine the FLP metabolites formed. The following are the main products found in the HPLC chromatogram for FLP: N-(2- [3-hydroxy-5- (trifluoromethyl)-2-pyridinyl]ethyl)-2trifluoromethyl)benzamide, 3-chloro -5-(trifluoro-methyl)-2- ethylformamide-pyridine and 2trifluoromethyl benzamide. Dong et al. (2016) examined the impacts of UV light on FLP photolysis and exposed 3 transformation products. Though, the FLP fate in water-treatment procedures has yet to be thoroughly investigated. 


\section{FLP biological disintegration}

454 The influence of various microbial activities on synthetic chemicals in the pedospheric zone is 455 manifested in the form of chemical alteration into daughter products (Gul and Ahmad 2020). In 456 both aerobic and anaerobic conditions, biological degradation of substances usually includes 457 biodeterioration and biodegradation. Although pesticide transformation can be accomplished 458 through adsorption, hydrolysis, or photolysis, these processes are also connected with the 459 development of daughter chemicals, which in many cases have more toxicity and persistence than 460 the parent material. Other than biological processes are distinguished by increased costs, more 461 complex operating requirements, and the creation of pervasive and toxic intermediates. As a result, 462 biologically triggered pesticide breakdown is a more efficient, cleaner, and environmentally 463 friendly process in which microbes act as biotechnological tools, detoxifying the environment from 464 hazardous compounds by releasing enzymes (Sun et al. 2020). In addition, soil temperature and 465 humidity are critical aspects in biodegradation processes, as the pedosphere region is characterized 466 by non-uniform temperatures due to various atmospheric and geological events (Kumar et al. 467 2017). In terms of rate fluctuation, pesticide biotransformation, particularly fungicide 468 biotransformation, is largely reliant on temperature (Reedich et al. 2017). The key degraders of 469 pesticides in the microbial world are bacteria, fungi, and actinomycetes (Ahmad 2020). In soil, synthetic pesticides are both anaerobically or aerobically metabolized by microbes. The 471 microorganisms often destroy the compounds and use them as an energy source for their existence

472 in the depend on the environment (Ahmad and Gul 2020). Because the microbial species are 473 fundamental degraders of a significant number of contaminants through excretion of particular 474 enzymatic compounds that usually break down chemical makeup, biological transformation is 475 performed with microbial biotechnological techniques. In a 35-day assay, the present laboratory476 based lithospheric consortia incorporating a replicated natural environment showed a remarkable 477 breakdown of FLP fungicide. The bio-degradative rate constant (k) differed between 0.120 and 478 0.065. Table 6 and Fig. 7 demonstrate that soil sample S5 degraded FLP at a significant rate (91 $479 \%)$ with 5.77 days half-life. Furthermore, since the physicochemical composition of soil affects 480 sorption, hydrolysis, and photolysis, the debasement mechanism in the soil is deeply and similarly 481 influenced by the physicochemical structure of the soil. S1 and S6 had the lowest rate of transformation $(62.7,65.2 \%)$ due to a high $\mathrm{pH}$, which makes micro-organisms less active at higher 
$483 \mathrm{pH}$ levels. S1 and S6 have a higher sand content and have less amount of OM compared to the 484 other samples, which have a higher proportion of OM.

\section{Conclusion}

486 The fungicide FLP's ecological fate was investigated in Pakistan's several ecological zones 487 employing pedospheric matrices collected randomly for evaluation of FLP transformations via 488 adsorption, desorption, hydrolysis, photolysis, and biodegradation. The findings aided insight into 489 FLP's behavior in lab-based tests that mimicked the natural environment of soils. In all of the 490 reactions examined, the physicochemical features of soils had an impact on the FLP fate of soil 491 matrices. The attachment of FLP molecules to soil particles was influenced by soil EC, $\mathrm{pH}$, textural 492 parameters, and OM. OM and clay indicated a positive relationship with adsorption, whilst $\mathrm{pH}$ was 493 found to have a negative relationship with the formation of adsorptive interactions. Hydrolytic and 494 photolytic pathways are two ways that adsorptive connections manifest themselves. The hydrolysis 495 and photolysis of FLP showed first-order reaction kinetics. FLP was successfully degraded by 496 biological consortia occurring inherently inside the tested soils, which released specific enzymes. 497 The method used in this study is distinguished by its cost-effectiveness, long-term viability, and 498 convenience of application for greener FLP remediation without the use of energy or chemicals. 499 The new work sheds light on the fungicide FLP fate within the pedospheric region. 
509 Compliance with ethical standards

510 Conflict of interest The authors declare that they have no conflict of interest.

511 Acknowledgements

512 The authors acknowledge the Department of Environmental Science, Fatima Jinnah Women

513 University, Pakistan, for providence of technical facilities.

514

515

516

517

518

519

520

521

522

523

524

525

526

527

528 


\section{References}

531 Abdelwaheb M, Jebali K, Dhaouadi H, Dridi-Dhaouadi S (2019) Adsorption of nitrate, phosphate,

532 nickel and lead on soils: Risk of groundwater contamination. Ecotoxicol Environ Saf 179:182-187

533 Aftab NF, Ahmad KS, Gul MM (2021) Sorptive and degradative assessments of environmentally 534 pestilential Benzimidazole fungicide Fuberidazole in pedosphere. Int J Environ Anal Chem 1-18.

535 Ahmad KS (2020) Environmental contaminant 2-chloro-N-(2, 6-diethylphenyl)-N536 (methoxymethyl) acetamide remediation via Xanthomonas axonopodis and Aspergillus niger. 537 Environ Res 182:109117

538 Ahmad KS, Gul P (2020) Fungicide isopyrazam degradative response toward extrinsically added 539 fungal and bacterial strains. J Basic Microbiol 60:484-493

540 Anwar S, Naz A, Ashraf MY, Malik A (2020) Evaluation of inorganic contaminants emitted from 541 automobiles and dynamics in soil, dust, and vegetations from major highways in Pakistan. Environ $542 \quad$ Sci Pollut Res 27:32494-32508

543 Arshad, A., Ahmed, A., Arshad, M., \& Shafiq, M (2017) Diversity of ornamental plants in Pattoki 544 nurseries, Punjab Pakistan: the major floral business hub of Pakistan. Pak J Weed Sci Res 23:463$545 \quad 472$

546 Briceño G, Lamilla C, Leiva B, Levio M, Donoso-Piñol P, Schalchli H, Gallardo F, Diez MC 547 (2020) Pesticide-tolerant bacteria isolated from a biopurification system to remove commonly used 548 pesticides to protect water resources. PloS one 15(6):e0234865

549 Conde-Cid M, Fernández-Calviño D, Nóvoa-Muñoz JC, Núñez-Delgado A, Fernández-Sanjurjo 550 MJ, Arias-Estévez M, Álvarez-Rodríguez E (2019) Experimental data and model prediction of 551 tetracycline adsorption and desorption in agricultural soils. Environ Res 177: 108607

552 Dal BoscoSampaio TCSC, Coelho SR, Cosmann NJ, Smanhotto A (2012) Efects of the organic 553 matter from swine wastewater on the adsorption and desorption of Alachlor in soil. J Environ Sci $554 \quad$ Health B 47:485-494 
555 D'andrea MF, Létourneau G, Rousseau AN, Brodeur JC (2020) Sensitivity analysis of the Pesticide 556 in Water Calculator model for applications in the Pampa region of Argentina. Sci Total Environ $557 \quad 698: 134232$

558 Dong B, Hu J (2016) Photodegradation of the novel fungicide fluopyram in aqueous solution: 559 kinetics, transformation products, and toxicity evolvement. Environ Sci Pollut Res 23:1909656019106

561 Faske TR, Brown K (2019) Movement of seed-and soil-applied fluopyram in soil columns. J $562 \quad$ Nematol 51

563 Feng Y, Huang Y, Zhan H, Bhatt P, Chen S (2020) An overview of strobilurin fungicide 564 degradation: Current status and future perspective. Front Microbio 11:389

565 Grabau ZJ, Liu C, Schumacher LA, Small IM, Wright DL (2021) In-furrow fluopyram nematicide 566 efficacy for Rotylenchulus reniformis management in cotton production. Crop Prot 140:105423

567 Gul MM, Ahmad KS (2020) Assessment of methyl 2-(\{[(4, 6-dimethoxypyrimidin-2-yl) 568 carbamoyl] sulfamoyl \} methyl) benzoate through biotic and abiotic degradation modes. Open 569 Chem 18:314-324

570 Gul P, Ahmad KS, Ali D (2020) Activated carbon processed from Citrus sinensis: Synthesis, 571 characterization and application for adsorption-based separation of toxic pesticides from soils. Sep 572 Sci Technol 56:2026-2035

573 Gul P, Ahmad KS, Gul MM (2020) Herbicide thiencarbazone-methyl pedospheric disposition 574 through sorption and degradation mechanisms in heterogenous soils. Environ Earth Sci 79:1-19

575 Gul P, Ahmad KS, Jaffri SB, Ali D (2021) Lithosphere-stationed fate and eco-detoxification 576 investigation of fungicidal agent Zoxamide possessing chlorinated benzamidic genesis. Int J 577 Environ Sci Technol 1-16

578 Gul P, Ahmad KS, Jaffri SB, Ali D (2021) Variegated Pedospheric Matrices Based Pyrzaole 579 Fungicide Chemico-physical and Biological Degradation Elucidation. Soil Sediment Contam 1-27 
Hasan M, Rashid MM, Hossain MM, Al Mesfer MK, Arshad M, Danish M, Lee M, El Jery A, Kumar N (2019) Fabrication of polyaniline/activated carbon composite and its testing for methyl orange removal: Optimization, equilibrium, isotherm and kinetic study. Polym Test 7:105909

Herrera H, Palma G, Almonacid L, Campos R, Fuentes A (2019) Improving soil simazine dissipation through an organic amendment inoculated with trametes versicolor. J Soil Sci Plant Nutr 19:262-269

Hu P, Guo C, Zhang Y, Lv J, Zhang Y, Xu J (2019) Occurrence, distribution and risk assessment of abused drugs and their metabolites in a typical urban river in north China. Front Environ Sci Eng 13:56

Ijaz M, Aftab M, Afsheen S, Iqbal T (2020) Novel Au nano-grating for detection of water in various electrolytes. Appl Nanosci 10:4029-4036

Iram S, Basri R, Ahmad KS, Jaffri SB (2019) Mycological assisted phytoremediation enhancement of bioenergy crops Zea mays and Helianthus annuus in heavy metal contaminated lithospheric zone. Soil Sed Contam 28:411-430

Iram S, Iqbal A, Ahmad KS, Jaffri SB (2020) Congruously designed eco-curative integrated farming model designing and employment for sustainable encompassments. Environ Sci Pollut Res 27:19543-19560

Iram S, Tariq I, Ahmad KS, Jaffri SB (2020) Helianthus annuus based biodiesel production from seed oil garnered from a phytoremediated terrain. Int J Ambient Energy 1-9.

Jaffri SB, Ahmad KS (2020) Interfacial engineering revolutionizers: perovskite nanocrystals and quantum dots accentuated performance enhancement in perovskite solar cells. Criti Rev Solid State Mater Sci 1-29.

Jaffri SB, Nosheen A, Iftikhar S, Ahmad KS (2019) Pedospheric environmental forensics aspects. In Trends of Environmental Forensics in Pakistan. Academic Press. (pp. 39-59).

Janaki P, Chinnusamy C, Sakthivel N, Nithya C (2015) Field dissipation of pendimethalin and alachlor in sandy clay loam soil and its terminal residues in sunfower (Helianthus annus L.). J Appl Nat Sci 7:709-713 
611 Kodešová R, Kočárek M, Kodeš V, Drábek O, Kozák J, Hejtmánková K (2011) Pesticide 612 adsorption in relation to soil properties and soil type distribution in regional scale. J Hazard Mater $613 \quad 186: 540-550$.

614 Kumar N, Mukherjee I, Sarkar B, Paul RK (2017) Degradation of tricyclazole: effect of moisture, 615 soil type, elevated carbon dioxide and Blue Green Algae (BGA). J Hazard Mater 321:517-527

616 Li X, Grey T, Price K, Vencill W, Webster T (2019) Adsorption, desorption and persistence of 617 fomesafen in soil. Pest Manag Sci 75:270-278

618 Liang P, Shen S, Xu Q, Wang S, Jin S, Lu H, Dong Y, Zhang J (2021) Design, synthesis biological 619 activity, and docking of novel fluopyram derivatives containing guanidine group. Bioorg Med 620 Chem 29:115846

621 Liu Y, Xu Z, Wu X, Gui W, Zhu G (2010) Adsorption and desorption behavior of herbicide diuron 622

623 624 625

626

627 628

629 630 631 on various Chinese cultivated soils. J Hazard Mater 178:462-468

Liu Y, Zhang W, Wang Y, Liu H, Zhang S, Ji X, Qiao K (2021) Oxidative stress, intestinal damage, and cell apoptosis: Toxicity induced by fluopyram in Caenorhabditis elegans. Chemosphere 286:131830

Matadha NY, Mohapatra S, Siddamallaiah L, Udupi VR, Gadigeppa S, Raja DP (2019) Uptake and distribution of fluopyram and tebuconazole residues in tomato and bell pepper plant tissues. Environ Sci Pollut Res 26:6077-6086

Meza P, Elgueta S, Sagredo B (2021) Evaluation of fluopyram for management of Meloidogyne ethiopica and migratory nematodes in commercial tomato greenhouses in the Metropolitan Region of Chile. Pest Manag Sci 77:2863-2869 
Muff J, MacKinnon L, Durant ND, Bennedsen LF, Rügge K, Bondgaard M, Pennell KD (2020) Solubility and reactivity of surfactant-enhanced alkaline hydrolysis of organophosphorus pesticide DNAPL. Environ Sci Pollut Res 27:3428-3439

Naeem H, Ahmad KS, Gul MM (2020) Agrochemical 2-chloro-2', 6'-diethyl-Nmethoxymethylacetanilide tranformative and sorptive demeanor in agriculturally significant pedospheric environs. Int J Environ Anal Chem 1-20.

Pérez-Mayán L, Ramil M, Cela R, Rodríguez I (2020) Multiresidue procedure to assess the occurrence and dissipation of fungicides and insecticides in vineyard soils from Northwest Spain. Chemosphere 261:127696

PPDB (2019) PPDB - Pesticides Properties DataBase. Agriculture \& Environment Research Unit (AERU), UK.

Reedich LM, Millican MD, Koch PL (2017) Temperature impacts on soil microbial communities and potential implications for the biodegradation of turfgrass pesticides. J Environ Qual 46:490497

Robatscher P, Eisenstecken D, Innerebner G, Roschatt C, Raifer B, Rohregger H, Hafner H, Oberhuber M (2019) 3-Chloro-5-trifluoromethylpyridine-2-carboxylic acid, a Metabolite of the Fungicide Fluopyram, Causes Growth Disorder in Vitis vinifera. J Agric Food Chem 67:72237231

Scheunert I (2018) Transport and transformation of pesticides in soil. In fate and prediction of environmental chemicals in soils, plants, and aquatic systems (pp. 1-22).

Shehzad MT, Murtaza G, Shafeeque M, Sabir M, Nawaz H, Khan MJ (2019) Assessment of trace elements in urban topsoils of Rawalpindi-Pakistan: a principal component analysis approach. Environ Monit Assess 191:65

Shivaramaiah HM (2014) Adsorption, desorption and movement of endosulfan in agricultural soil. Int J Food Vet Sci 4:53-61.

Siddiqui S, Safi MW, Tariq A, Rehman NU, Haider SW (2020) GIS Based Universal Soil Erosion Estimation in District Chakwal Punjab, Pakistan. Int J Econ Environ Geol 11: 30-36 
Siraj H, Ahmad KS, Jaffri SB, Sohail M (2020) Synthesis, characterization and electrochemical investigation of physical vapor deposited barium sulphide doped iron sulphide dithiocarbamate thin films. Microelectron Eng 233:111400.

Song S, Zhang C, Chen Z, Wei J, Tan H, Li X (2019) Hydrolysis and photolysis of bentazone in aqueous abiotic solutions and identification of its degradation products using quadrupole time-offlight mass spectrometry. Environ Sci Pollut Res 26:10127-10135

Sun Y, Kumar M, Wang L, Gupta J, Tsang DC (2020) Biotechnology for soil decontamination: opportunity, challenges, and prospects for pesticide biodegradation. In Bio-based materials and biotechnologies for eco-efficient construction Woodhead Publishing. (pp. 261-283).

Tahir MB, Ahmad A, Iqbal T, Ijaz M, Muhammad S, Siddeeg SM (2020) Advances in photocatalysis approach for the removal of toxic personal care product in aqueous environment. Environ. Dev. Sustain. 22(7):6029-6052.

Takeshita V, Mendes KF, Pimpinato RF, Tornisielo VL (2020) Adsorption Isotherms of Diuron and Hexazinone in Drinking Water Using Four Agro-Industrial Residues. Planta Daninha 38.

Waisen P, Wang KH, Uyeda J, Myers RY (2021) Effects of fluopyram and azadirachtin integration with sunn hemp on nematode communities in zucchini, tomato and sweet potato in Hawaii. J Nematol 53.

Waldo BD, Grabau ZJ, Mengistu TM, Crow WT (2019) Nematicide effects on non-target nematodes in bermudagrass. J Nematol 51.

Wang XQ, Liu J, Zhang N, Yang H (2020) Adsorption, mobility, biotic and abiotic metabolism and degradation of pesticide exianliumi in three types of farmland. Chemosphere 254:126741

Yavari S, Sapari NB, Malakahmad A, Yavari S (2019) Degradation of imazapic and imazapyr herbicides in the presence of optimized oil palm empty fruit bunch and rice husk biochars in soil. J Hazard Mater 366:636-642

Zafar A, Ahmad KS, Jaffri SB, Sohail M (2020) Physical vapor deposition of SnS: PbSdithiocarbamate chalcogenide semiconductor thin films: elucidation of optoelectronic and electrochemical features. Phosphorus Sulfur Silicon Relat Elem 196: 36-46 
686 Zahid Z, Iftikhar S, Ahmad KS, Gul MM (2018) Low-cost and environmental-friendly Triticum 687 aestivum-derived biochar for improving plant growth and soil fertility. Commun Soil Sci Plant 688 Anal 49: 2814-2827

689 Zahra T, Ahmad KS, Shaheen I, Azhar S, Jaffri SB (2017) Determining the adsorption and 690 desorption behavior of thiabendazole fungicide for five different agricultural soils. Soil Environ 691 36: $13-19$

692 Zhou J, Liang S, Cui Y, Rong Y, Song J, Lv D (2021) Study on environmental behaviour of 693 fluopyram in different banana planting soil. Sci Rep 11:1-10

694 Zhou W, Zhang Y, Li W, Jia H, Huang H, Li B (2019) Adsorption isotherms, degradation kinetics, 695 and leaching behaviors of cyanogen and hydrogen cyanide in eight texturally different agricultural 696 soils from China. Ecotoxicol Environ Saf 185:109704.

697

698

699

700

701

702

703

704

705

706

707 


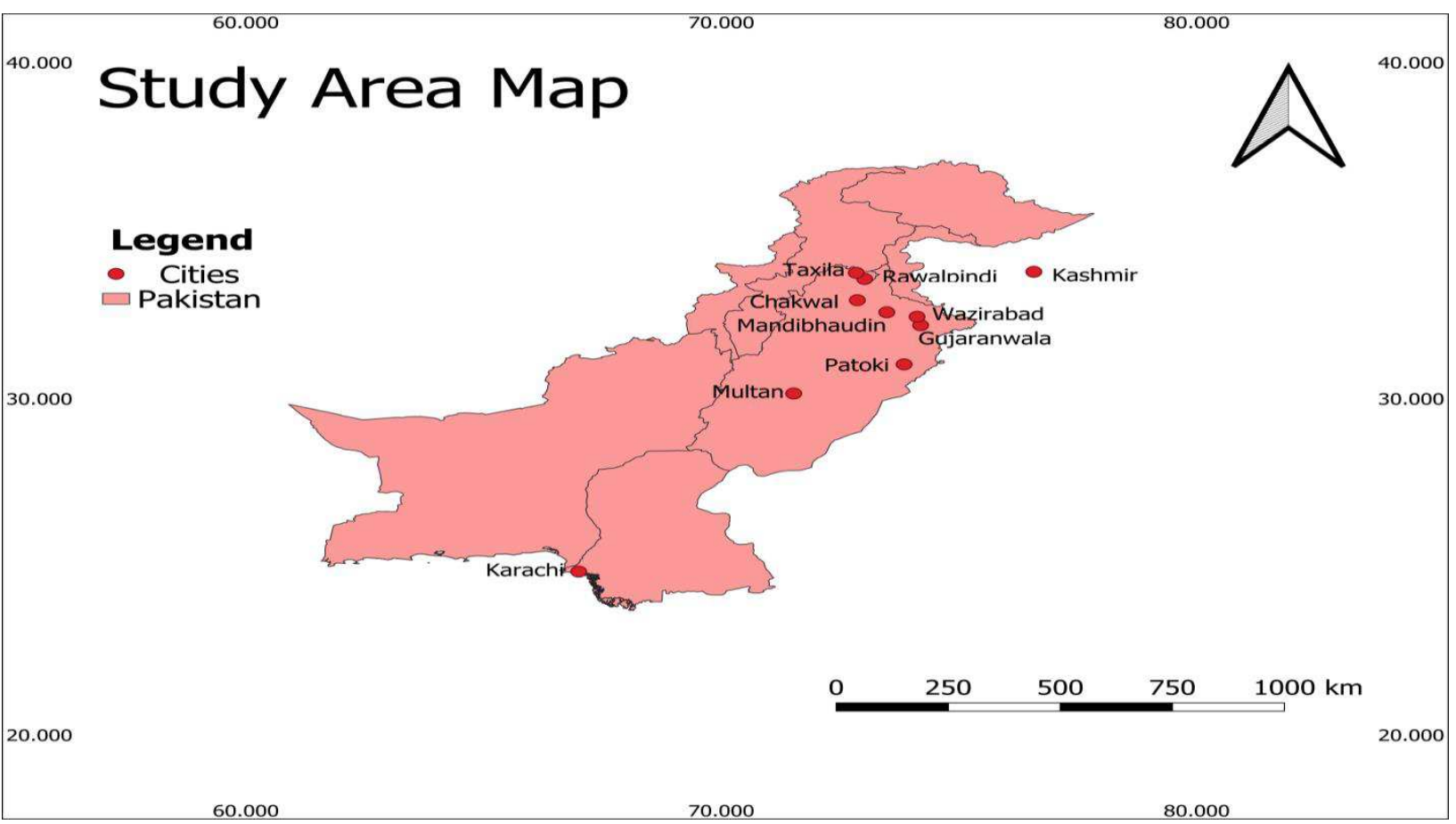

Fig. 1 Fate evaluation of the fungicide FLP in pedosphere environs shown on a territorial map of Pakistan

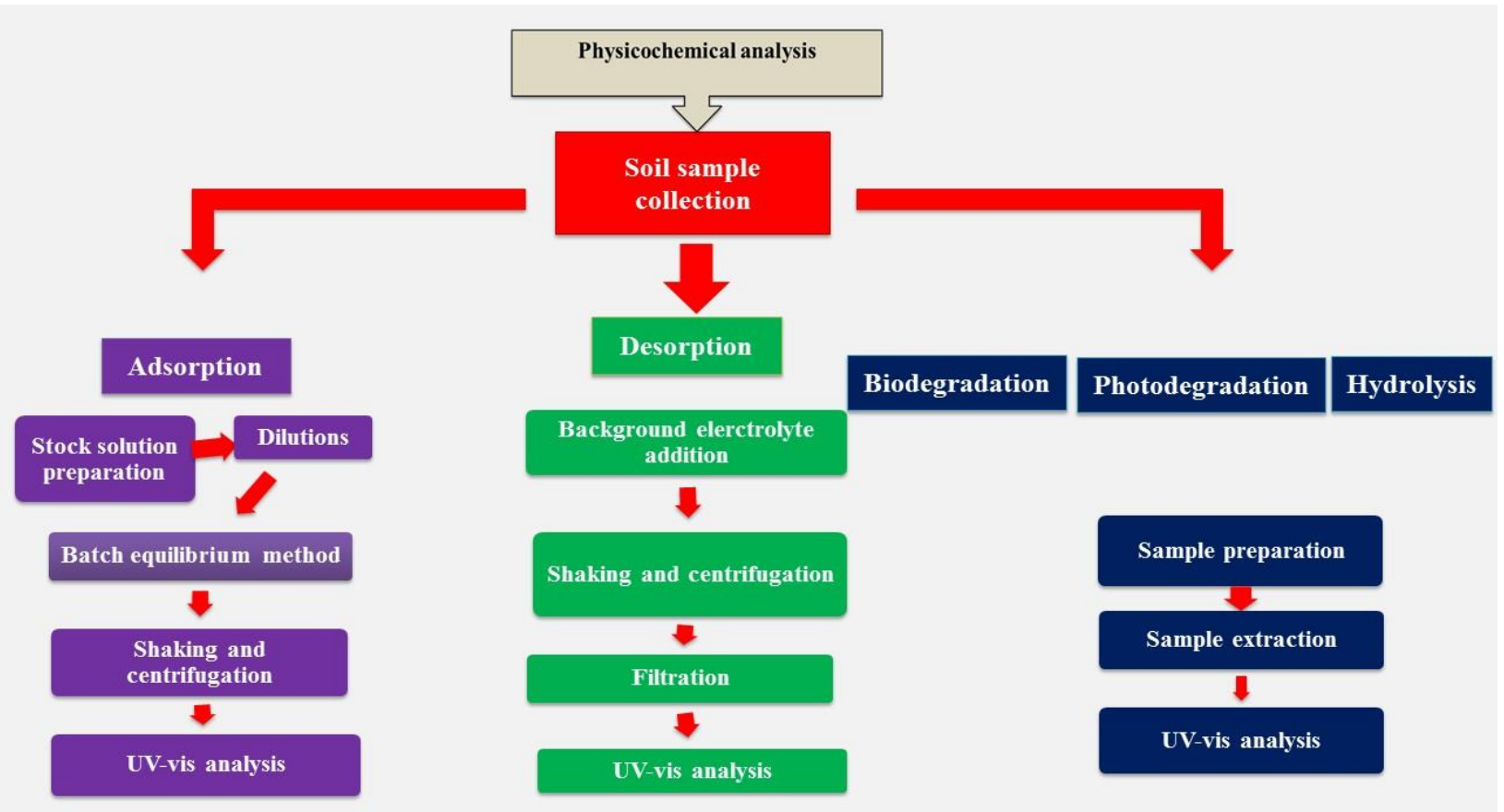

712 Fig. 2. Flowchart representation of the comprehensive methodology of fungicide FLP sorption and

713 degradation 


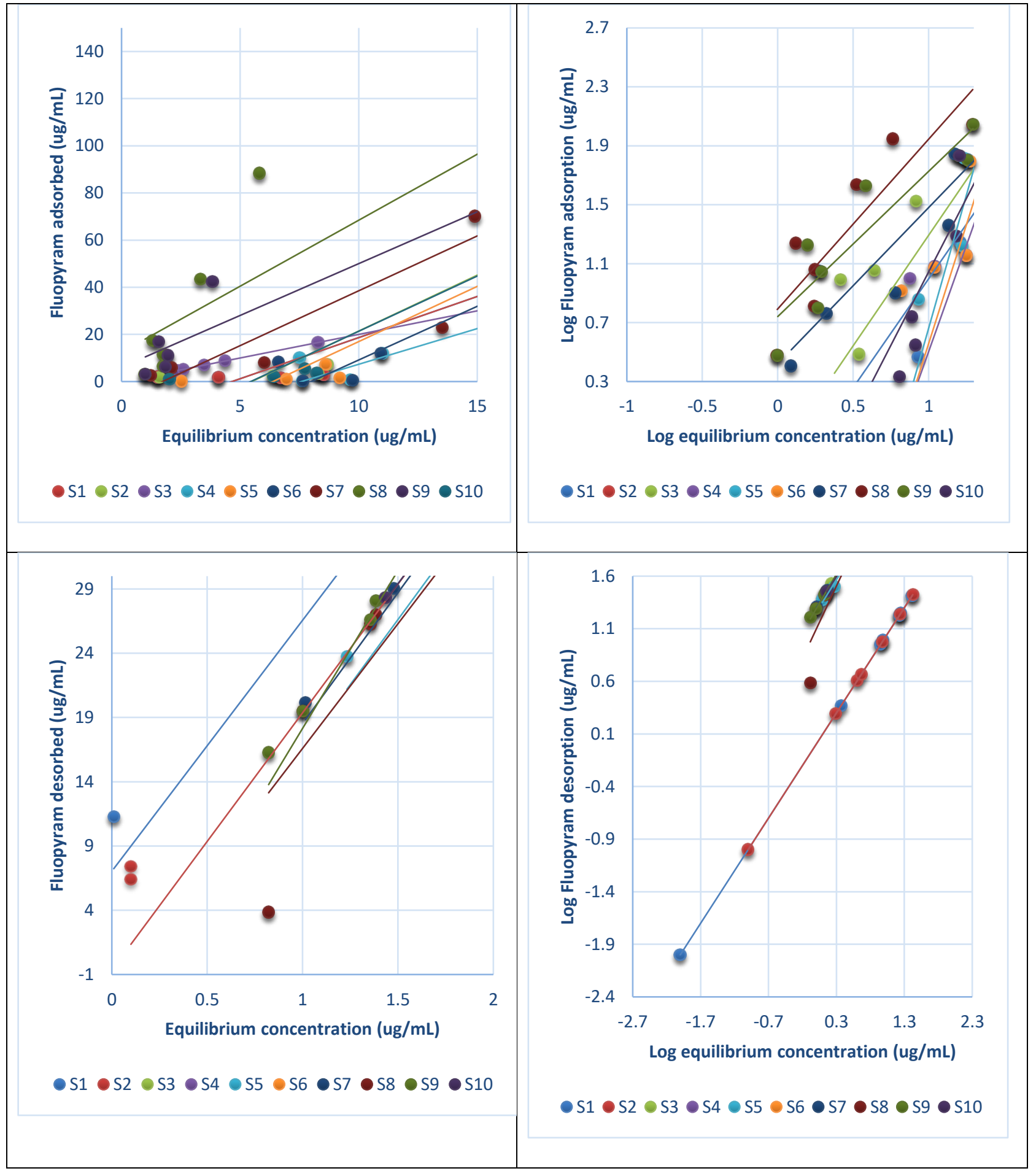

Fig. 3 Comparative FLP adsorption isothermal representation in selected pedospheric matrices, linear and Freundlich: (a) Linear adsorption model for FLP (b) Freundlich adsorption model for FLP (c) Linear

717 desorption model for FLP (d) Freundlich desorption model for FLP 


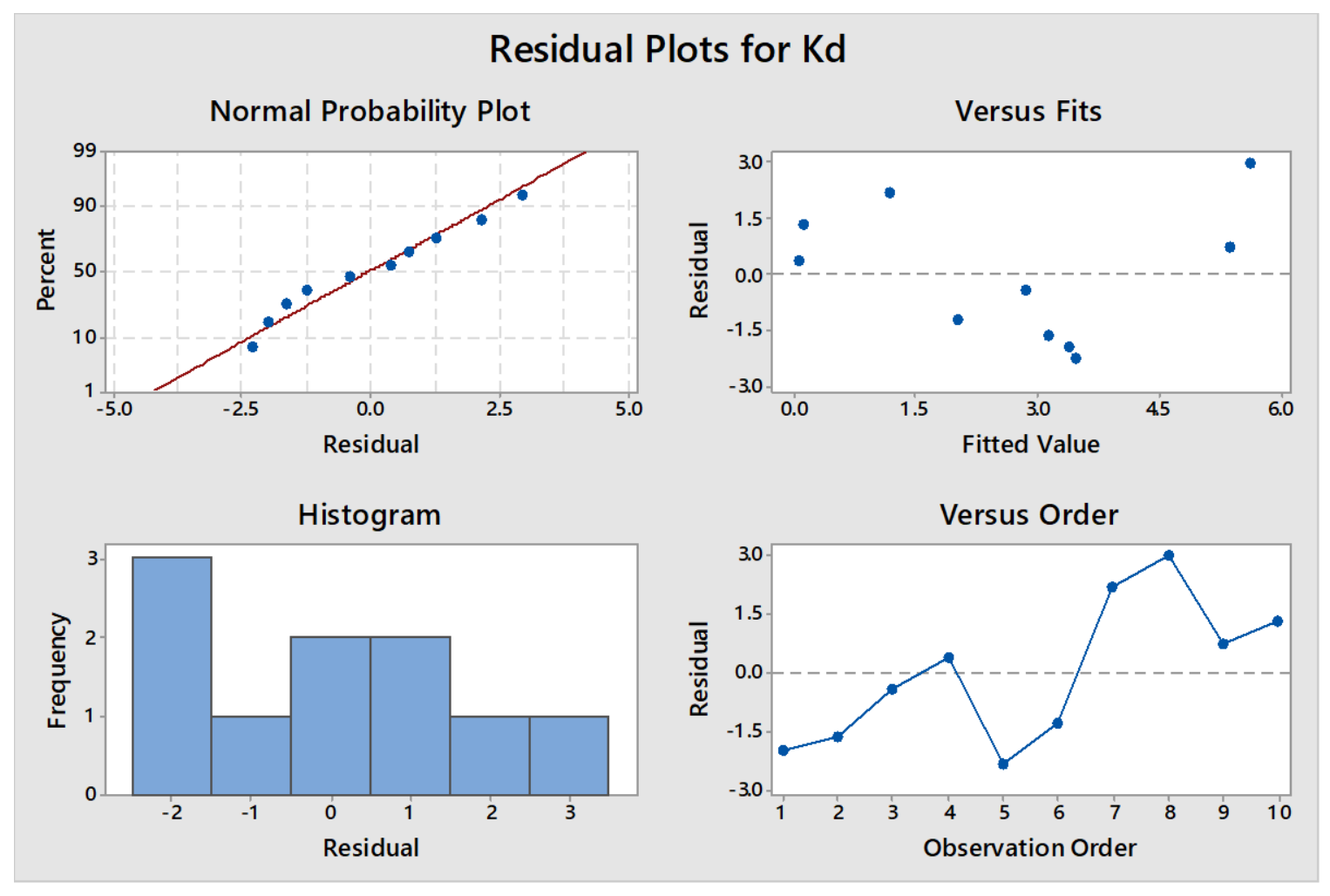

Fig. 4 Physicochemical parameters of soils compared to FLP adsorption coefficients, ANOVA plots for FLP adsorption distribution coefficient 

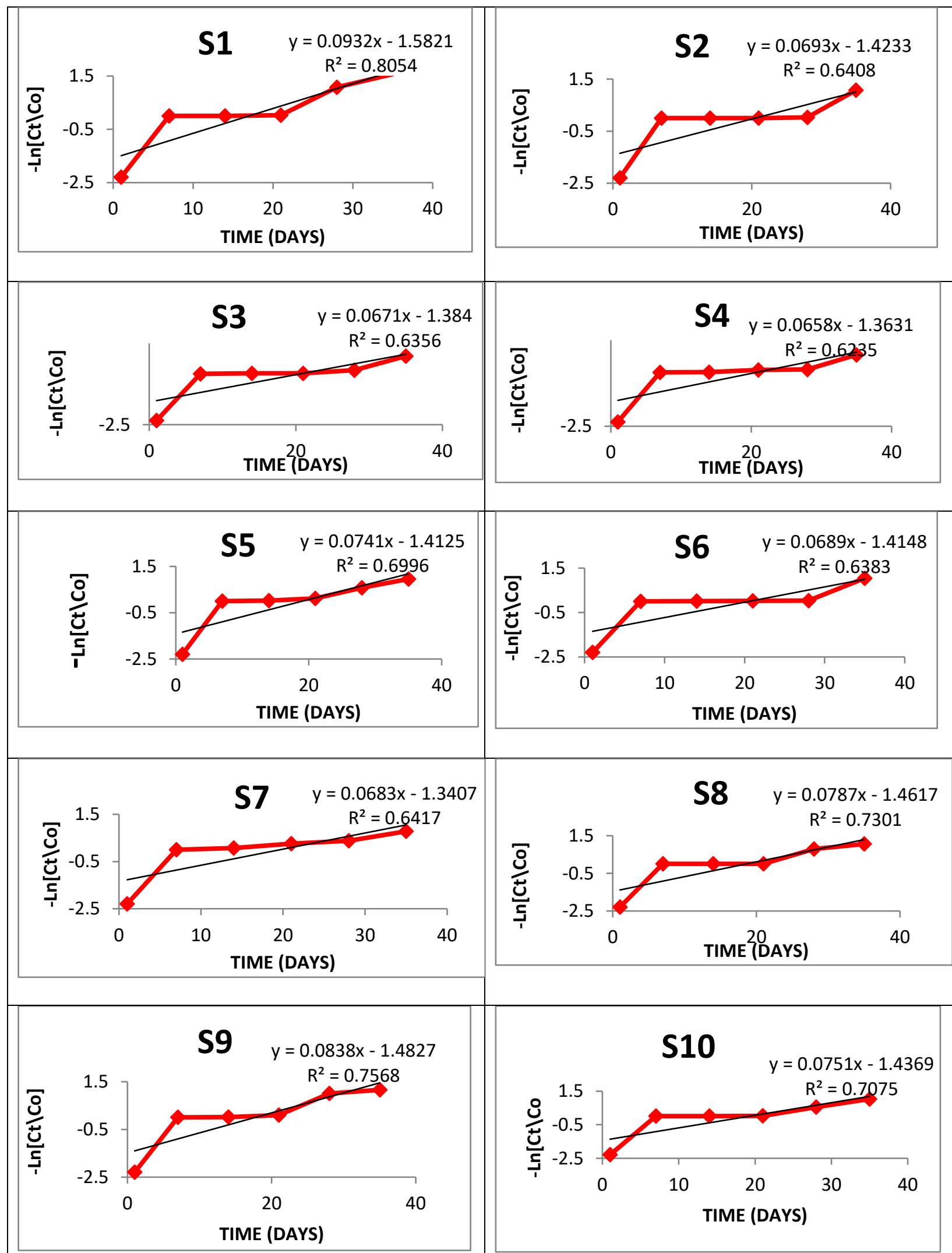


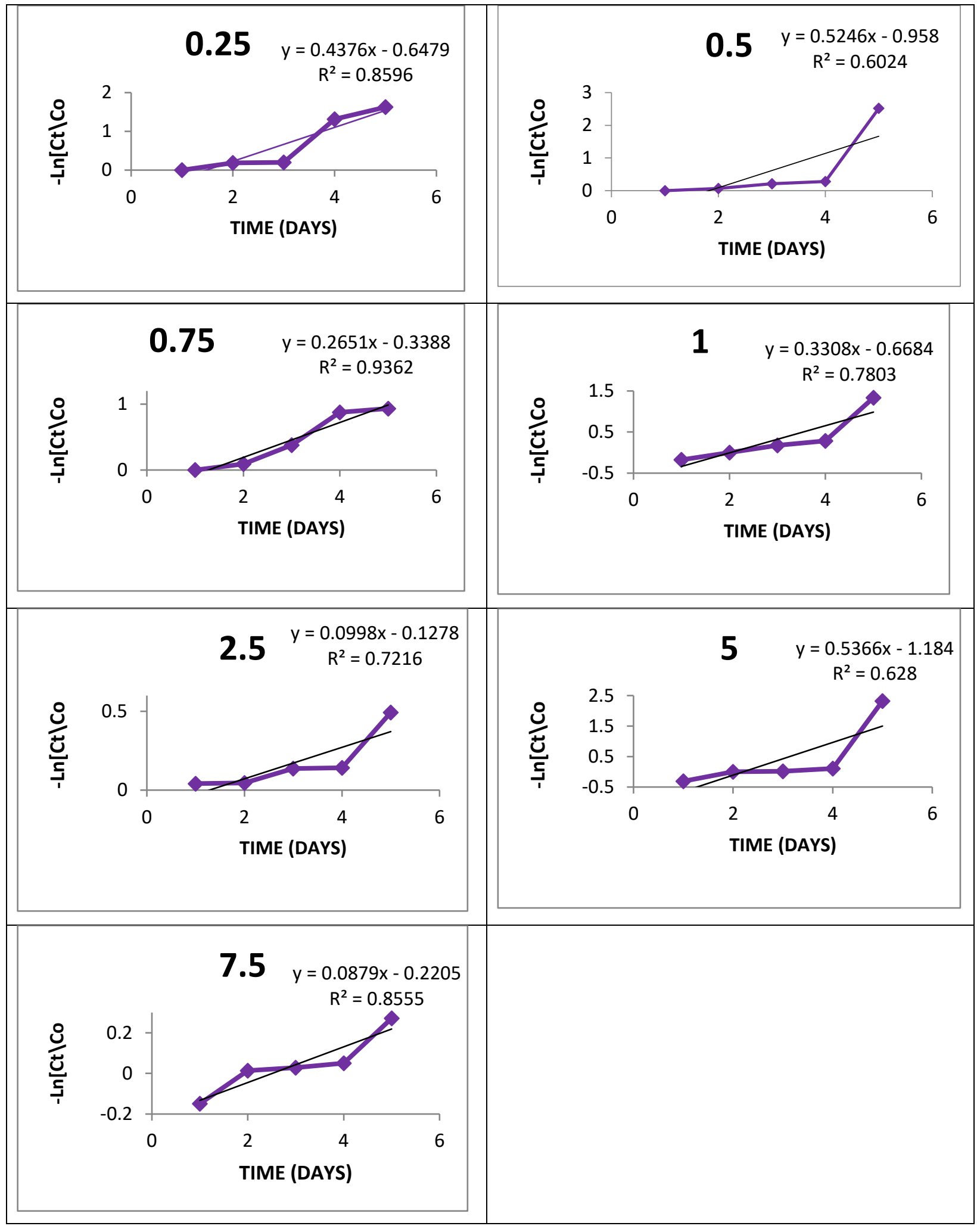




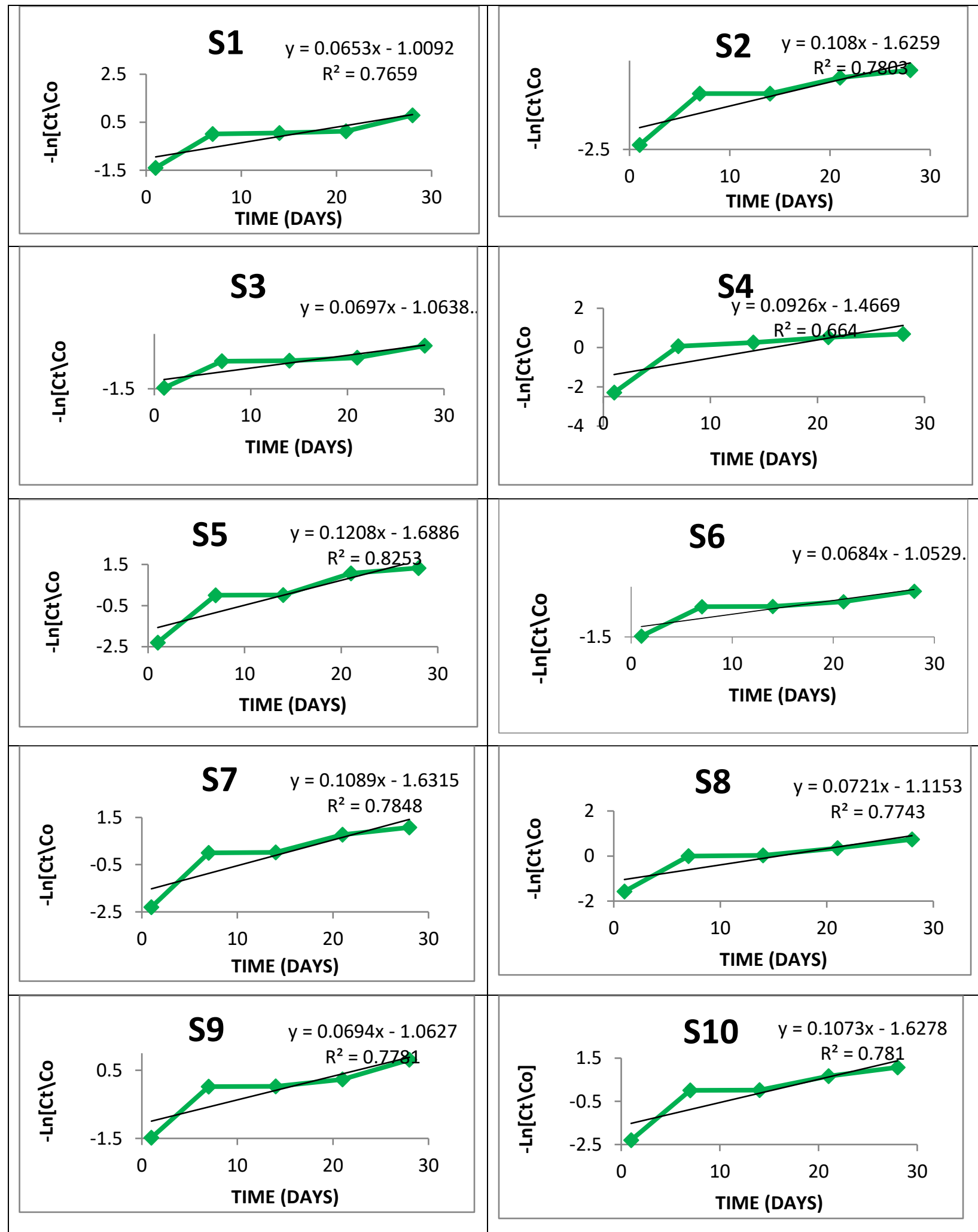

737 Fig. 7 FLP's UV-Vis half-life and biodegradation plots in ten soils as revealed by each soil microbe consortia 738 without exogenous microbe 


\begin{tabular}{|c|c|c|c|c|c|c|c|c|c|c|c|c|c|c|c|}
\hline$\#$ & $\begin{array}{l}\text { Samp } \\
\text { le }\end{array}$ & pH & $\begin{array}{l}\mathbf{O} \\
\mathbf{M}\end{array}$ & $\begin{array}{l}\text { Satur } \\
\text { ation }\end{array}$ & $\begin{array}{l}\text { Text } \\
\text { ure }\end{array}$ & Sand & Silt & Clay & $\begin{array}{l}\mathrm{EC} \\
\mathrm{Sm}^{-1}\end{array}$ & $\begin{array}{l}\text { TO } \\
\text { C }\end{array}$ & $\begin{array}{l}\mathrm{TN} \\
\%\end{array}$ & Cd & $\mathbf{C u}$ & $\mathbf{P b}$ & $\mathrm{Fe}$ \\
\hline & & & & & & & & & & $\%$ & & & & & \\
\hline \multirow[t]{2}{*}{$\mathrm{S} 1$} & Taxila & 7.7 & 0. & 55 & Loa & 45 & 35 & 21 & 0.94 & 0.5 & 0.8 & 0.0 & 1.4 & 1.1 & 17. \\
\hline & & 2 & 90 & & $\mathrm{~m}$ & & & & & 23 & 5 & 06 & & 6 & 9 \\
\hline \multirow[t]{2}{*}{$\mathrm{S} 2$} & Gujra & 7.6 & 0. & 40 & Loa & 35 & 40 & 22 & 0.69 & 0.4 & 0.8 & 0.0 & 1.1 & 1.3 & 19.1 \\
\hline & nwala & 9 & 85 & & $\mathrm{~m}$ & & & & & 94 & 0 & 060 & & 7 & \\
\hline \multirow[t]{2}{*}{ S3 } & Karac & 7.5 & 0. & 42 & Loa & 40 & 35 & 23 & 0.89 & 0.4 & 0.7 & 0.0 & 0.8 & 0.9 & 17. \\
\hline & hi & 6 & 80 & & $\mathrm{~m}$ & & & & & 65 & 5 & 119 & 3 & 9 & 7 \\
\hline \multirow[t]{2}{*}{ S4 } & Wazir & 7.7 & 0. & 55 & Loa & 45 & 37 & 17 & 1.12 & 0.1 & 0.2 & 0.0 & 1.3 & 1.2 & 17. \\
\hline & abad & 3 & 30 & & $\mathrm{~m}$ & & & & & 74 & 5 & 059 & 4 & 4 & 8 \\
\hline \multirow[t]{3}{*}{ S5 } & Multa & 7.3 & 0. & 55 & Clay & 38 & 29 & 33 & 1.61 & 0.5 & 0.8 & 0.1 & 2.8 & 4.1 & 19. \\
\hline & $\mathrm{n}$ & 0 & 90 & & Loa & & & & & 23 & 5 & 625 & 8 & 2 & 2 \\
\hline & & & & & $\mathrm{m}$ & & & & & & & & & & \\
\hline \multirow[t]{4}{*}{ S6 } & Mand & 7.7 & 0. & 42 & Loa & 43 & 39 & 18 & 1.04 & 0.3 & 0.6 & 0.0 & 1.5 & 1.6 & 17. \\
\hline & $\mathrm{i}$ & 2 & 65 & & $\mathrm{~m}$ & & & & & 77 & 0 & 059 & & 6 & 9 \\
\hline & bahau & & & & & & & & & & & & & & \\
\hline & ddin & & & & & & & & & & & & & & \\
\hline \multirow[t]{2}{*}{ S7 } & Chak & 7.7 & 0. & 40 & Loa & 42 & 41 & 17 & 1.13 & 0.2 & 0.4 & 0.0 & 2 & 1.5 & 16. \\
\hline & wal & 0 & 50 & & $\mathrm{~m}$ & & & & & 90 & 5 & 127 & & & 3 \\
\hline \multirow[t]{3}{*}{ S8 } & Pattok & 7.6 & 1. & 40 & Clay & 21 & 37 & 36 & 0.93 & 0.7 & 1.2 & 0.0 & 1.2 & 0.6 & 19 \\
\hline & $\mathrm{i}$ & 1 & 30 & & Loa & & & & & 5 & 5 & 045 & 241 & 14 & \\
\hline & & & & & $\mathrm{m}$ & & & & & & & & & & \\
\hline \multirow[t]{2}{*}{ S9 } & Rawal & 7.5 & 1. & 43 & Loa & 41 & 36 & 19 & 1.43 & 0.7 & 1.2 & 0.0 & 4.1 & 5.7 & 16 \\
\hline & pindi & 0 & 25 & & $\mathrm{~m}$ & & & & & 26 & 0 & 110 & & & \\
\hline
\end{tabular}




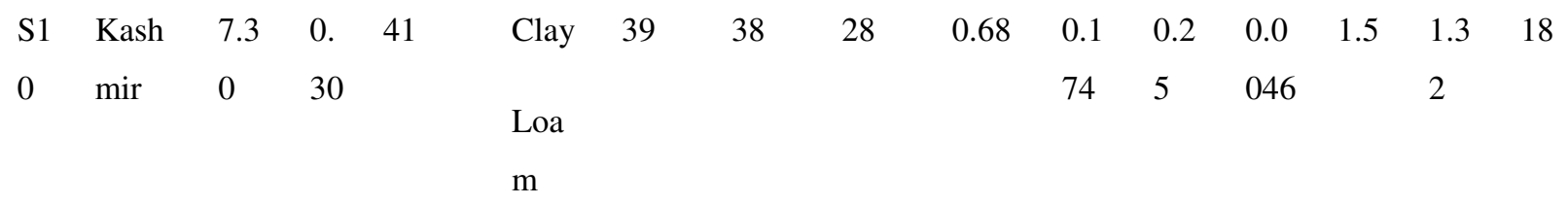

740 Table 2 The utilization of linear and Freundlich models to determine the adsorptive characteristics of FLP on 741 ten diverse soils.

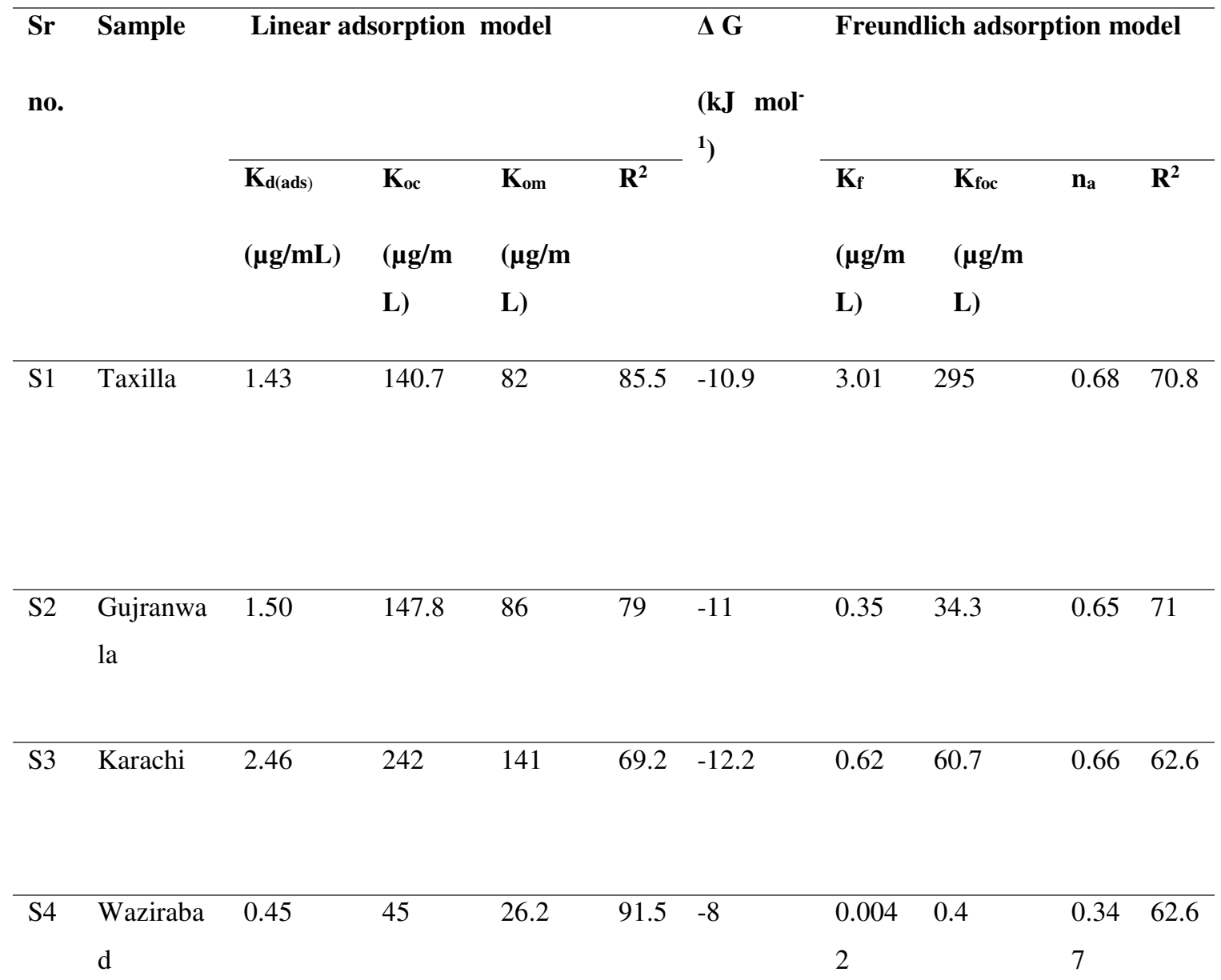

\begin{tabular}{|c|c|c|c|c|c|c|c|c|}
\hline \multirow[t]{2}{*}{ S5 } & Multan & 1.19 & 117.2 & 68.3 & 79.5 & -10.4 & $0.001 \quad 0.1$ & $0.27 \quad 94.8$ \\
\hline & & & & & & & 12 & 7 \\
\hline
\end{tabular}

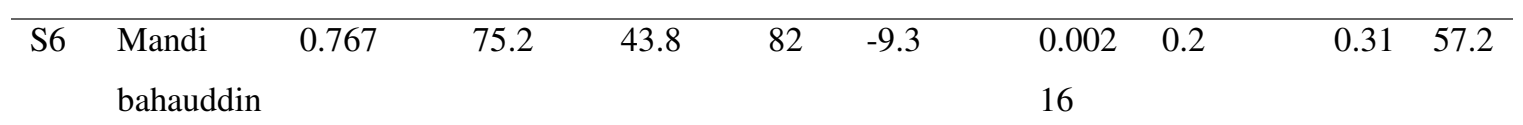




\begin{tabular}{lllllllllll}
\hline S7 & Chakwal & 3.354 & 328.8 & 191.6 & 82 & -13 & 4.82 & 472.5 & 0.54 & 73 \\
& & & & & & & & & &
\end{tabular}

\begin{tabular}{lllllllllll}
\hline S8 & Pattoki & 8.61 & 844 & 492 & 75 & -15.3 & 6.2 & 607.843 & 0.86 & 78 \\
& & & & & & & & & 8 &
\end{tabular}

\begin{tabular}{lllllllllll}
\hline S9 & Rawalpin & 6.13 & 601.6 & 350.6 & 85 & -14.5 & 5.5 & 539.21 & 1.01 & 83 \\
& di & & & & & & & & &
\end{tabular}

\begin{tabular}{lllllllllll}
\hline S1 & Kashmir & 1.435 & 140.7 & 82 & 83 & -10.9 & 8.86 & 868.3 & 0.50 & 85 \\
0 & & & & & & & & & & 2
\end{tabular}

742

743

744

745

746

747

748

749

750

751

752

753 
754 Table 3 The utilization of linear and Freundlich models to determine the desorptive characteristics of FLP on 755 ten diverse soils.

\begin{tabular}{|c|c|c|c|c|c|}
\hline \# & Sample & $\begin{array}{l}\mathbf{K}_{\mathbf{d}(\mathrm{des})} \\
(\boldsymbol{\mu g} / \mathbf{m L})\end{array}$ & $\begin{array}{l}\mathbf{K}_{\mathbf{f}} \\
(\boldsymbol{\mu g} / \mathbf{m L})\end{array}$ & $\mathbf{n}_{\mathbf{d}}$ & $\mathbf{H}$ \\
\hline $\mathrm{S} 1$ & Taxilla & 4.207 & 74.47 & 2.13 & 3.146 \\
\hline $\mathrm{S} 2$ & Gujranwala & 10.07 & 32.13 & 1.28 & 1.975 \\
\hline S3 & Karachi & 20.15 & 19.95 & 0.99 & 1.494 \\
\hline S4 & Wazirabad & 19.85 & 20.5 & 1.01 & 2.91 \\
\hline S5 & Multan & 19.304 & 17.98 & 0.96 & 3.48 \\
\hline S6 & $\begin{array}{l}\text { Mandi } \\
\text { bahauddin }\end{array}$ & 19.89 & 19.54 & 0.99 & 3.20 \\
\hline S7 & Chakwal & 20.03 & 19.76 & 0.99 & 1.828 \\
\hline S8 & Pattoki & 19.14 & 12.38 & 0.72 & 0.835 \\
\hline S9 & Rawalpindi & 20.73 & 19.36 & 0.905 & 0.89 \\
\hline $\mathrm{S} 10$ & Kashmir & 19.877 & 19.72 & 0.99 & 1.98 \\
\hline
\end{tabular}


756 Table 4 FLP fungicide degradation information by hydrolytic experiment in various soils.

$\begin{array}{lllll}\text { No. } & \text { Location } & (\mathrm{k}) & \left(\mathrm{t}_{1 / 2}\right) \text { (days) } & (\%) \\ \text { S1 } & \text { Taxila } & 0.093 & 7.45 & 93.1 \\ \text { S2 } & \text { Gujranwala } & 0.069 & 10 & 66.9 \\ \text { S3 } & \text { Karachi } & 0.067 & 10.3 & 66.7 \\ \text { S4 } & \text { Wazirabad } & 0.065 & 10.6 & 66.5 \\ \text { S5 } & \text { Multan } & 9.36 & 81.2 \\ \text { S6 } & \text { Mandi bahauddin } & 0.068 & 10.1 & 67.2 \\ \text { S7 } & \text { Chakwal } & 0.068 & 10.1 & 77.4 \\ \text { S8 } & \text { Pattoki } & 0.078 & 8.8 & 84.5 \\ \text { S9 } & \text { Rawalpindi } & 0.083 & 8.34 & 89.8 \\ \text { S10 } & \text { Kashmir } & 0.075 & 9.24 & 80.4\end{array}$


Table 5 FLP fungicide degradation information by photolytic degradation experiment.

\begin{tabular}{|c|c|c|c|c|}
\hline No. & Concentration & $\begin{array}{l}\text { Photodegradation } \\
\text { rate constant }(\mathrm{k})\end{array}$ & $\begin{array}{l}\text { Half-life } \quad\left(\mathrm{t}_{1 / 2}\right) \\
\text { (days) }\end{array}$ & Percentage degradation $(\%)$ \\
\hline 1 & 0 & 0.297 & 2.33 & 96 \\
\hline 2 & 0.25 & 0.437 & 1.58 & 81 \\
\hline 3 & 0.5 & 0.524 & 1.32 & 93 \\
\hline 4 & 0.75 & 0.265 & 2.61 & 74 \\
\hline 5 & 1 & 0.330 & 2.1 & 24 \\
\hline 6 & 2.5 & 0.099 & 7 & 44 \\
\hline 7 & 5 & 0.536 & 1.29 & 44 \\
\hline 8 & 7.5 & 0.087 & 7.96 & 91 \\
\hline
\end{tabular}

771

772

773

774

775

776

777

778

779

780

781

782 
783 Table 6 FLP fungicide degradation information by soil biodegradation experiment in ten soils.

\begin{tabular}{|c|c|c|c|c|}
\hline No. & Region & $\begin{array}{l}\text { Biodegradation } \\
\text { rate constant }(\mathrm{k})\end{array}$ & Half-life $\left(\mathrm{t}_{1 / 2}\right)$ (days) & $\begin{array}{l}\text { Percentage } \\
(\%)\end{array}$ \\
\hline S1 & Taxila & 0.065 & 10.6 & 62.7 \\
\hline $\mathrm{S} 2$ & Gujranwala & 0.108 & 6.41 & 84 \\
\hline $\mathrm{S} 3$ & Karachi & 0.069 & 10 & 66.2 \\
\hline S4 & Wazirabad & 0.092 & 7.5 & 78.5 \\
\hline S5 & Multan & 0.120 & 5.77 & 91 \\
\hline S6 & Mandi bahauddin & 0.068 & 10 & 65.2 \\
\hline S7 & Chakwal & 0.108 & 6.4 & 84.6 \\
\hline S8 & Pattoki & 0.072 & 9.6 & 67.3 \\
\hline S9 & Rawalpindi & 0.069 & 10 & 66.5 \\
\hline S10 & Kashmir & 0.107 & 6.47 & 83 \\
\hline
\end{tabular}




\section{Supplementary Files}

This is a list of supplementary files associated with this preprint. Click to download.

- SUPPLYMENTARYMATERIAL.docx 